\title{
Differences in Linear Energy Transfer Affect Cell-killing and Radiosensitizing Effects of Spread-out Carbon-ion Beams
}

\author{
SHINTARO SHIBA ${ }^{1,2}$, MASARU WAKATSUKI ${ }^{1}$, TATSUYA OHNO ${ }^{3}$ and TAKASHI NAKANO ${ }^{1}$ \\ ${ }^{1}$ QST Hospital, National Institutes for Quantum and Radiological Science and Technology, Chiba, Japan; \\ ${ }^{2}$ Gunma University Heavy-Ion Medical Center, Maebashi, Japan; \\ ${ }^{3}$ Department of Radiation Oncology, Gunma University Graduate School of Medicine, Maebashi, Japan
}

\begin{abstract}
Background/Aim: The cell-killing and radiosensitizing effects of carbon-ion (C-ion) beams with low linear energy transfer (LET) are underexplored. We aimed to demonstrate the cell-killing effects of ${ }^{60}$ Co gamma rays and $C$ ion beams at various LET values and the radiosensitizing effect of C-ion beams at various LET and cisplatin levels. Materials and Methods: Human uterine cervical cancer cells were irradiated with ${ }^{60}$ Co gamma rays and $C$-ion beams at different levels of LET, with and without cisplatin treatment. Results: LowLET C-ion beams had a superior cell-killing effect compared to ${ }^{60}$ Co gamma rays. Survival curves under low-LET C-ion beams were more similar to that of ${ }^{60} \mathrm{Co}$ gamma rays than that of highLET C-ion beams. Cisplatin significantly reduced cell survival after 1,2, and $3 \mathrm{~Gy}$ C-ion beam irradiations at LET values of $13 / 30 / 70 \mathrm{keV} / \mu \mathrm{m}, 13 / 30 \mathrm{keV} / \mathrm{um}$, and $13 \mathrm{keV} / \mu \mathrm{m}$, respectively. Conclusion: Low-LET C-ion beams combined with cisplatin have higher radiosensitizing effects than high-LET C-ion beams.

Carbon-ion radiotherapy (C-ion RT) was initiated in 1994 to treat various cancer types, and favorable treatment outcomes have been reported (1-10). These outcomes are due to its localizing properties and more significant biological advantages than X-ray RT, including distal tail-off due to the Bragg peak, a sharp lateral penumbra, and higher relative biological effectiveness (RBE) due to high linear energy transfer (LET) in the Bragg peak $(1,11,12)$. Additionally, C-ion beams with high LET have a superior cell-killing effect against radioresistant and hypoxic cells (13).
\end{abstract}

This article is freely accessible online.

Correspondence to: Masaru Wakatsuki, QST Hospital, National Institutes for Quantum and Radiological Science and Technology, 4-9-1, Anagawa, Inage-ku, Chiba, Japan. Tel: +81 432063306, Fax: +81 432063345, e-mail: wakkun100@yahoo.co.jp

Key Words: Carbon-ion beams, linear energy transfer, cell-killing effect, radiosensitizing effect, HeLa cells.
Recently, in photon therapy, concurrent chemoradiotherapy has become standard treatment for several types of cancer in expectation of a sensitizing effect of RT and preventing micrometastasis throughout the body (14-16). RT with C-ions, combined with anticancer drugs has been performed for uterine cervical cancer, pancreatic cancer, and malignant melanoma of head and neck $(2,8,17-19)$ for example. The radiosensitizing effect of $\mathrm{C}$-ion beams combined with anticancer drugs has also been reported in vitro, with high LET (70 keV/ $\mu \mathrm{m}$ or higher) $\mathrm{C}$-ion beams $(20,21)$.

In the clinical use of $\mathrm{C}$-ion $\mathrm{RT}$, the narrow radiation peaks are swept over an extended region by a ridge filter to create the spread-out Bragg peak (SOBP) corresponding to the size of the target volume; an SOBP has an LET of between 10 $\mathrm{keV} / \mu \mathrm{m}$ and $120 \mathrm{keV} / \mu \mathrm{m}(11,22,23)$ (Figure 1). Although high-LET C-ion beams have shown higher RBE and superior cell-killing effect compared to X-ray and ${ }^{60} \mathrm{Co}$ gamma-ray irradiation in vitro, there are not many studies that compared the cell-killing effects of $\mathrm{X}$-ray or ${ }^{60} \mathrm{Co}$ gamma-ray and $\mathrm{C}$ ion beam irradiation with lower LET (24). We hypothesized that anticancer drugs would have a higher sensitizing effect when combined with $\mathrm{C}$-ion beam irradiation with a lower LET than a higher one. Furthermore, to date, there are no reports on the radiosensitizing effect of low-LET C-ion beams and anticancer drugs in combination. Here, we aimed to compare, via in vitro experiments, the cell-killing effect of ${ }^{60} \mathrm{Co}$ gamma-ray and $\mathrm{C}$-ion beam irradiation at different LET levels, and the radiosensitizing effect of $\mathrm{C}$-ion beams at various LET values when combined with cisplatin.

\section{Materials and Methods}

Cell line. The human cervical adenocarcinoma cell line, HeLa, was obtained from the American Type Culture Collection (Manassas, VA, USA). This cell line possesses wild-type P53 gene. Cells were maintained in $25-\mathrm{cm}^{2}$ culture flasks at $37^{\circ} \mathrm{C}$ in a humidified atmosphere with $5 \% \mathrm{CO}_{2}$ in Eagle's Minimum Essential Medium containing $20 \%$ heat-inactivated fetal bovine serum, $1 \%$ L-glutamine, and $1 \%$ penicillin-streptomycin. The medium and serum were purchased from Sigma Chemical Co. (St. Louis, MO, 


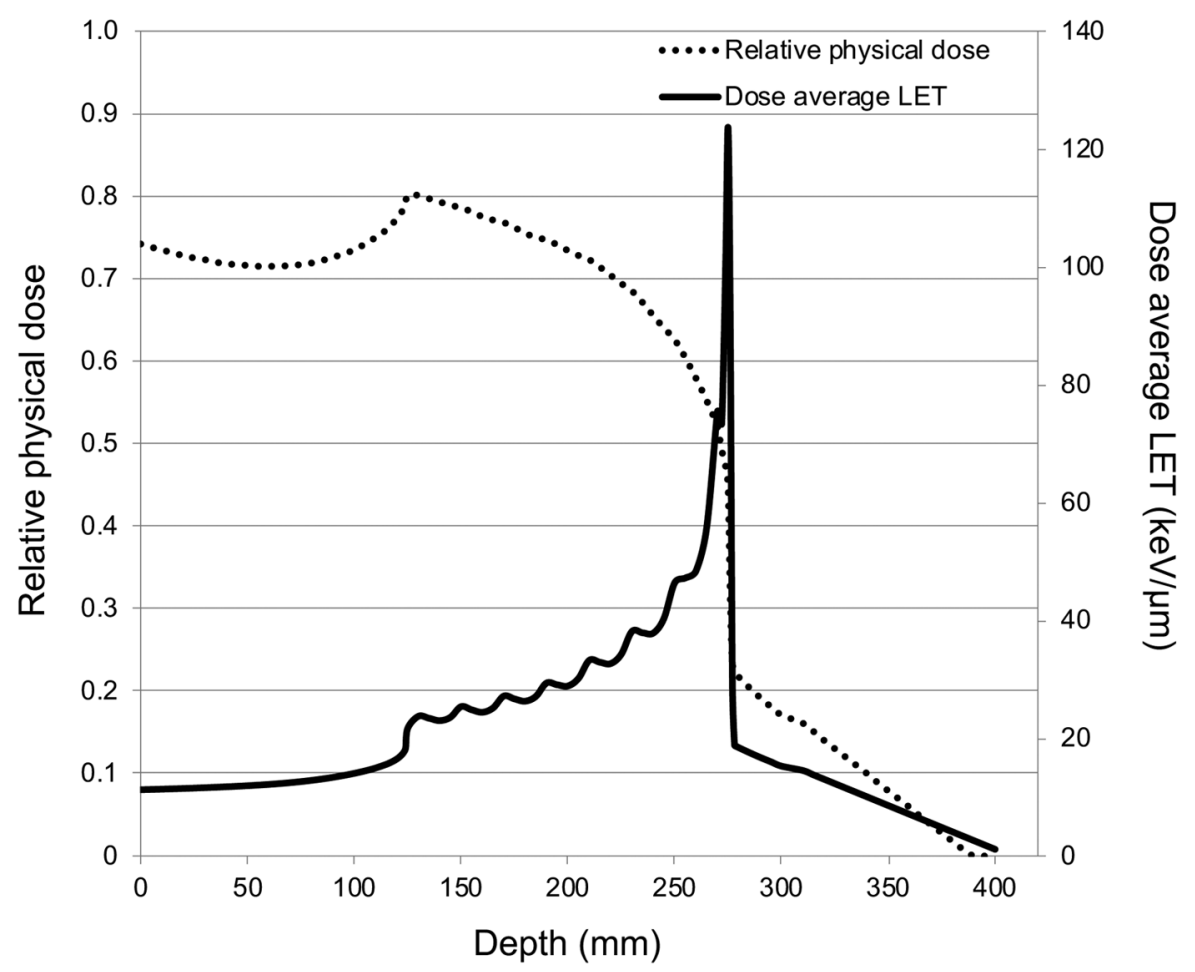

Figure 1. Relative physical dose and dose average linear energy transfer (LET) in 15-cm spread-out Bragg peak for carbon-ion beam.

USA). Cells were passaged before confluence and at passage 5 were used for all experiments.

${ }^{60}$ Co gamma-ray and $C$-ion beam irradiation. Irradiation was performed at the National Institute of Radiological Sciences. The dose of ${ }^{60} \mathrm{Co}$ gamma-ray irradiation was $2.5 \mathrm{~Gy} / \mathrm{min}$. The cells were irradiated with different doses (1, 2, 3, and 4 Gy). C-Ions were accelerated at $290 \mathrm{MeV} /$ nucleon using a Heavy-ion Medical Accelerator at Chiba synchrotron. The irradiation system and biophysical characteristics were reported previously (22-24). The cells were irradiated at the above doses with LET of $13 \mathrm{keV} / \mu \mathrm{m}, 30$ $\mathrm{keV} / \mu \mathrm{m}$, and $70 \mathrm{keV} / \mu \mathrm{m}$ of $\mathrm{C}$-ion beams.

Anticancer drug. Cisplatin was purchased from Nippon Kayaku Ltd. (Tokyo, Japan). Cells were exposed to $5 \mu \mathrm{M}$ cisplatin 1 hour before irradiation for the combination group, the dose of which was approximately the median effective dose (half-maximal inhibitory concentration). The drug-containing medium was replaced with drug-free medium immediately after irradiation.

Clonogenic cell-survival assay. The effect of treatment on cell survival was evaluated using the clonogenic cell-survival assay. Cells were grown under standard conditions. Three weeks after irradiation, cells were fixed with methanol and stained with crystal violet. Colonies consisting of at least 50 cells were counted. Survival fractions were calculated as the ratio of surviving colonies per number of plated cells. Cell survival fractions were normalized to the survival fraction in the absence of irradiation. For the radiosensitizing effect, data for cells exposed to $\mathrm{C}$-ion beams and cisplatin were normalized to the survival fraction in cisplatin alone. We also compared the survival fractions between cells exposed or unexposed to cisplatin in combination with $\mathrm{C}$-ion beams at different doses and LET levels. The sensitizer enhancement ratio (SER), as an indicator of the radiosensitizing effect of cisplatin, was calculated as the ratio of cell survival with irradiation alone to that with irradiation and cisplatin. Each experiment was performed in quadruple and repeated on three different days.

Statistical analysis. The data from three independent experiments are expressed as the mean \pm standard deviation. Statistical significance was determined using Student's $t$-test. We determined the strength of associations of SER with LET, and with dose of Cion RT using Pearson correlation coefficient. All statistical analyses were performed using the Statistical Package of the Social Sciences software, version 25.0 (IBM Inc., Armonk, NY, USA). A value of $p<0.05$ was defined as statistically significant.

\section{Results}

Cell-survival curve. The survival of HeLa cells irradiated with ${ }^{60} \mathrm{Co}$ gamma rays and $\mathrm{C}$-ion beams with various LET levels was assessed utilizing clonogenic survival assay. Figure 2 shows the survival curves under different irradiation schemes. C-Ion beams of $13 \mathrm{keV} / \mu \mathrm{m}$ had a superior cell-killing effect to ${ }^{60} \mathrm{Co}$ gamma rays. In contrast, RT with $13 \mathrm{keV} / \mu \mathrm{m} \mathrm{C}$-ion beams 


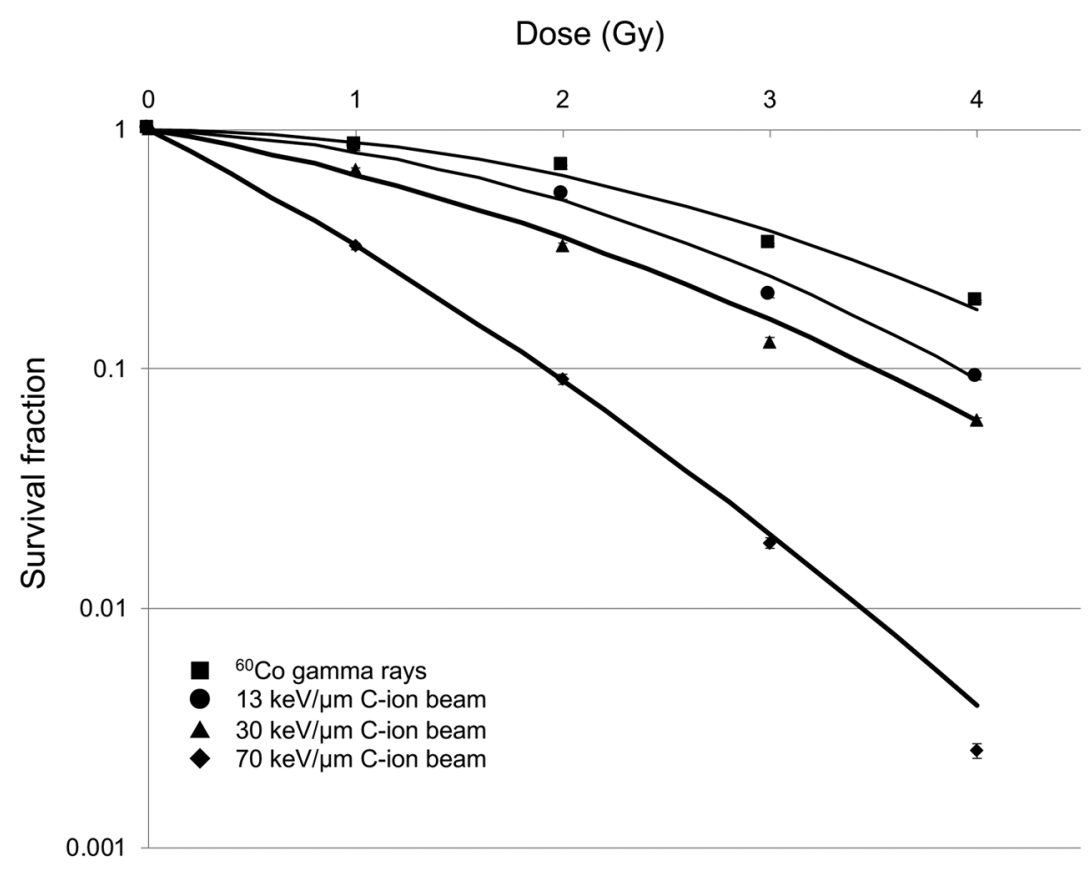

Figure 2. Survival curves of HeLa cells after ${ }^{60} \mathrm{Co}$ gamma-ray or carbon-ion (C-ion) beam irradiation at different linear energy transfer levels. Data are presented as the mean \pm standard deviation, fitted to the linear-quadratic model.

produced a survival curve more similar to that for ${ }^{60} \mathrm{Co}$ gamma rays than those with $30 \mathrm{keV} / \mu \mathrm{m}$ and $70 \mathrm{keV} / \mu \mathrm{m} \mathrm{C}$-ion beams.

Figure 3 shows the survival rate after each dose of $\mathrm{C}$-ion $\mathrm{RT}$ and the comparison between RT with $\mathrm{C}$-ion beams alone and at different LET values combined with cisplatin. A dose of 1 Gy $\mathrm{C}$-ion beams in combination with cisplatin significantly reduced the cell survival fraction compared with C-ion RT alone at different LET levels (by 7-31\%; $p<0.001$ for $13 \mathrm{keV} / \mu \mathrm{m}, p<0.001$ for $30 \mathrm{keV} / \mu \mathrm{m}$, and $p<0.05$ for 70 $\mathrm{keV} / \mu \mathrm{m})$. At a dose of $2 \mathrm{~Gy}, \mathrm{C}$-ion RT combined with cisplatin significantly reduced the cell survival fractions than $\mathrm{C}$-ion RT alone at an LET of 13 and $30 \mathrm{keV} / \mu \mathrm{m}(p<0.001$ and $p<0.05$, respectively); however, at $70 \mathrm{keV} / \mu \mathrm{m}$, the difference was not significant. At a dose of 3 Gy C-ion RT, the combination again significantly reduced cell survival compared with C-ion RT alone at an LET of $13 \mathrm{keV} / \mu \mathrm{m}$ $(p<0.01)$. In contrast, at $30 \mathrm{keV} / \mu \mathrm{m}$ and $70 \mathrm{keV} / \mu \mathrm{m}$, the difference was not significant. At a dose of $4 \mathrm{~Gy}$, there were no significant differences between the survival fractions after C-ion RT at different LET levels.

Sensitizer enhancement ratio. Table I shows the SER of cisplatin combined with $\mathrm{C}$-ion RT at each LET and dose. These results showed that the radiosensitizing effect of $\mathrm{C}$ ion RT were inversely related to LET and dose of C-ion RT. There were strong negative correlations between SER and LET ( $r=-0.79$ for $1 \mathrm{~Gy}, \mathrm{r}=-0.79$ for $2 \mathrm{~Gy}, \mathrm{r}=-0.79$ for $3 \mathrm{~Gy}$, and $\mathrm{r}=-0.97$ for $4 \mathrm{~Gy}$, respectively), and SER and dose of Cion RT ( $\mathrm{r}=-0.96$ for $13 \mathrm{keV} / \mu \mathrm{m}, \mathrm{r}=-0.93$ for $30 \mathrm{keV} / \mu \mathrm{m}$, and $\mathrm{r}=-0.99$ for $70 \mathrm{keV} / \mu \mathrm{m}$, respectively).

\section{Discussion}

We demonstrated the cell-killing effect of ${ }^{60} \mathrm{Co}$ gamma-ray and $\mathrm{C}$-ion beam irradiation at various LET, and the in vitro radiosensitizing effect of $\mathrm{C}$-ion beams at various LET levels when combined with cisplatin. Previous in vitro experiments revealed small radiosensitizing effects of high-LET C-ion beams $(70 \mathrm{keV} / \mu \mathrm{m}$ or higher) combined with anticancer drugs $(20,21)$. Kubo et al. reported that radiosensitizing effects were observed with $50 \mathrm{keV} / \mu \mathrm{m}$ LET of C-ion beams combined with carboplatin and paclitaxel (25). However, our study is the first to report radiosensitizing effects of $\mathrm{C}$-ion beams with lower LET combined in combination with cisplatin. Our results showed that differences in LET led to different radiosensitizing effects, especially for the low-LET C-ion beams combined with cisplatin; however, use of C-ion beams with higher LET combined with cisplatin had lower radiosensitizing effect.

Few reports compared the cell-killing effect of ${ }^{60} \mathrm{Co}$ gamma ray or $\mathrm{X}$-ray and $\mathrm{C}$-ion beam irradiation at various LET levels. A previous study reported survival fractions under ${ }^{60} \mathrm{Co}$ gamma-ray and low LET of C-ion irradiation were similar to those of ${ }^{60} \mathrm{Co}$ gamma-ray and high-LET of C-ion irradiation (24). In our experiments, similar results 


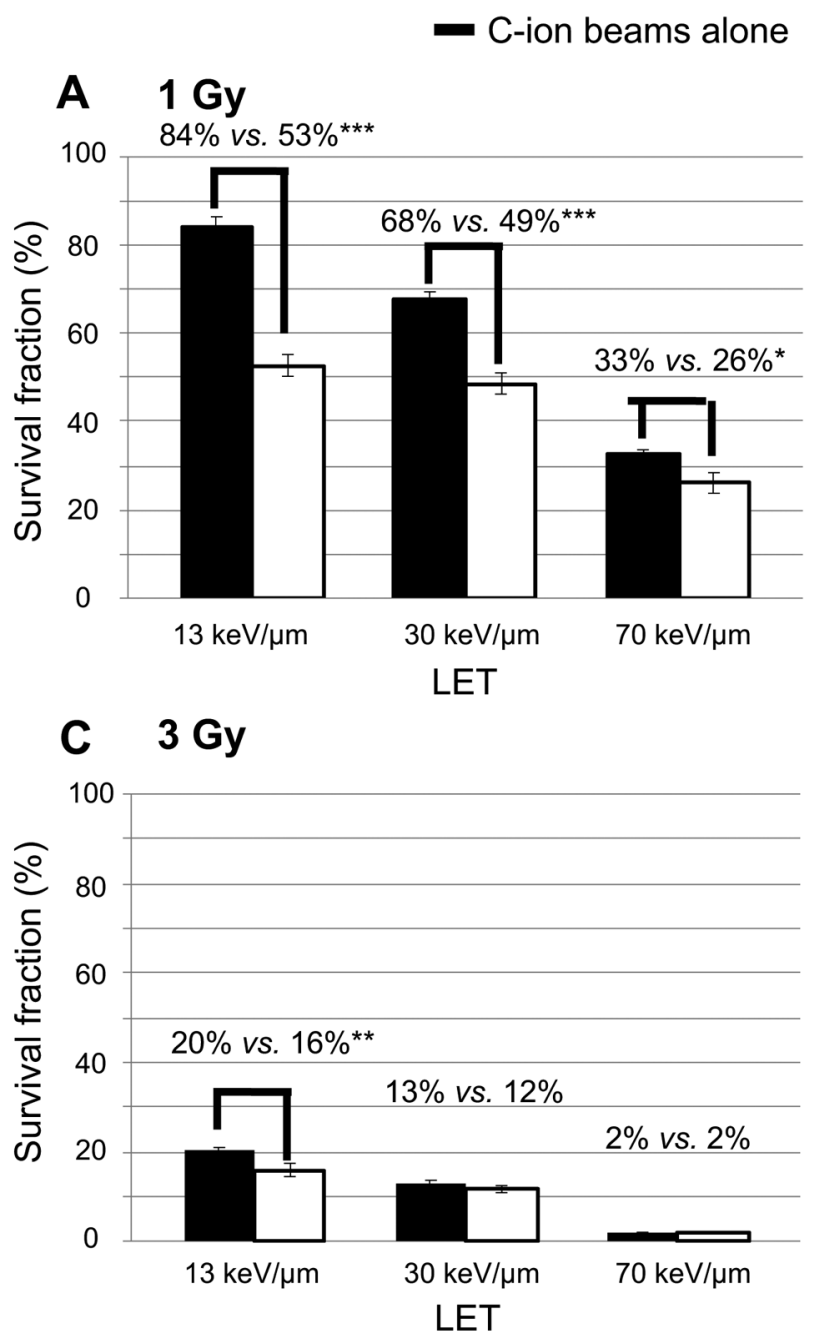

$\square$ C-ion beams + cisplatin

\section{B 2 Gy}
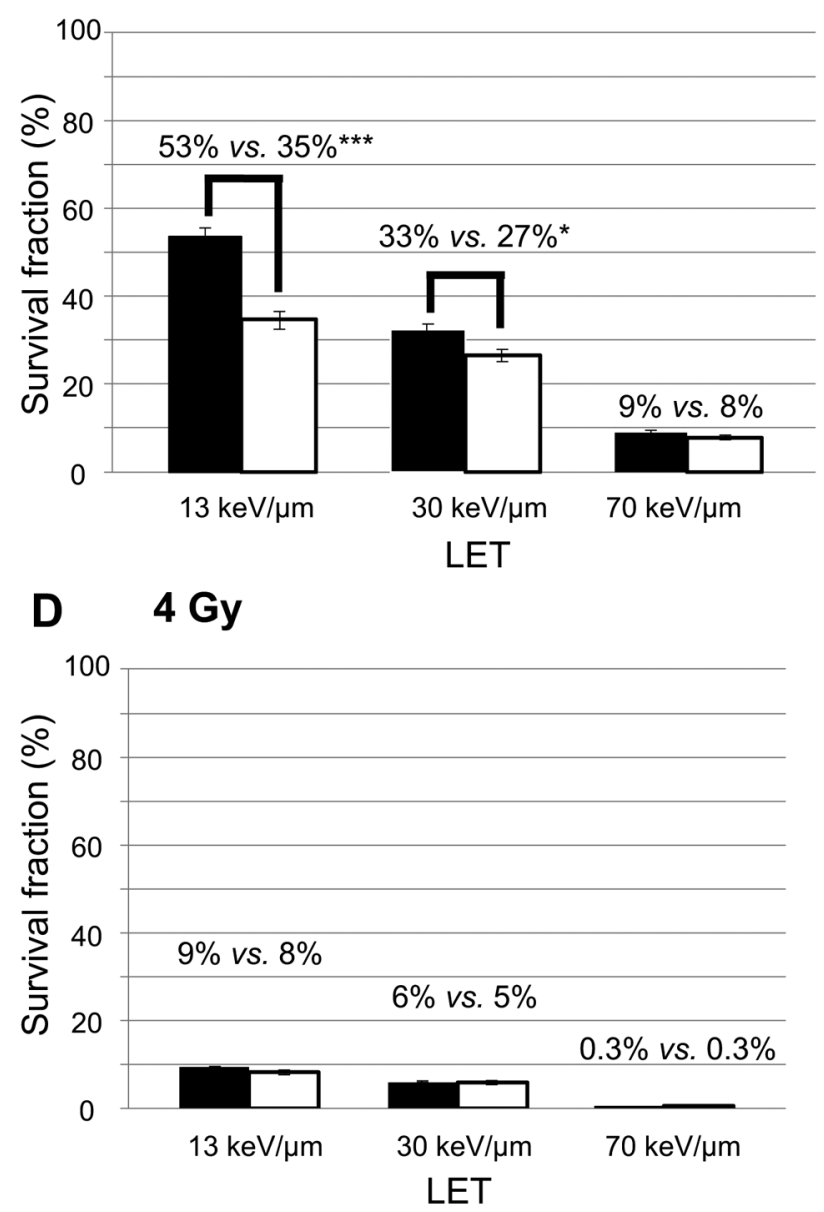

Figure 3. The survival rate of HeLa cells after $1 G y(A), 2 G y(B), 3 G y(C)$, and $4 G y(D)$ of carbon-ion (C-ion) beam irradiation at different linear energy transfer levels alone and with cisplatin. Data are presented as the mean \pm standard deviation. Significantly different at $* p<0.05, * * p<0.01$, and $* * * p<0.001$.

were obtained. Additionally, we hypothesized that anticancer drugs would sensitize tumor cells in combination with $\mathrm{C}$-ion $\mathrm{RT}$ at a lower LET because ${ }^{60} \mathrm{Co}$ gamma-ray and X-ray irradiation have radiosensitizing effects (26) and we proved our hypothesis via several in vitro experiments. In clinical settings, a large SOBP (i.e. $15-\mathrm{cm}$ ) is used for large tumors, and in the prophylactic irradiation of uterine cervical cancer, a large SOBP includes low-LET components $(2,8)$ (Figure 1). To date, biological and physical characteristics of highLET C-ion beams have been reported by several researchers (11, 20-24). However, higher LET components are included in the narrow area of the distal side on the $\mathrm{C}$-ion beam pass and lower LET components are included in the premaximal side of the target on the $\mathrm{C}$-ion beam pass $(11,24)$ (Figure 1). For example, the LET of the beam center in 15-cm SOBP C- ion beams is approximately $30 \mathrm{keV} / \mu \mathrm{m}$, and that of the proximal side center with the same beams is lower $(11,24)$ (Figure 1). Our results suggested that these lower LET components might drive the radiosensitizing effect of $\mathrm{C}$-ion beams in combination with anticancer drugs in a clinical setting and increase the therapeutic effect.

From our results, the radiosensitizing effect we observed might have been due to LET. Oike et al. reported the formation of complex DNA double-strand breaks (DSBs), which are more challenging to repair than single-strand breaks, is related to LET and that high LET C-ion RT induced complex DSBs (27). Cisplatin is a DNA-damaging and DNArepair-inhibiting anticancer agent $(28,29)$. The SER was higher with low LET in our study, and cisplatin might have impaired the repair of single/DSBs induced by low-LET C-ion 
Table I. Sensitizer enhancement ratio (SER) of cisplatin at each linear energy transfer (LET) level and dose of carbon-ion (C-ion) irradiation.

\begin{tabular}{lcccc}
\hline & \multicolumn{5}{c}{ SER at C-ion dose } \\
\cline { 2 - 5 } LET & 1 Gy & 2 Gy & 3 Gy & 4 Gy \\
\hline $13 \mathrm{keV} / \mu \mathrm{m}$ & $1.59 \pm 0.11$ & $1.56 \pm 0.13$ & $1.35 \pm 0.20$ & $1.26 \pm 0.24$ \\
$30 \mathrm{keV} / \mu \mathrm{m}$ & $1.40 \pm 0.09$ & $1.23 \pm 0.11$ & $1.08 \pm 0.07$ & $1.09 \pm 0.11$ \\
$70 \mathrm{keV} / \mu \mathrm{m}$ & $1.38 \pm 0.24$ & $1.19 \pm 0.17$ & $1.05 \pm 0.15$ & $0.94 \pm 0.08$ \\
\hline
\end{tabular}

Data are presented as the mean \pm standard deviation.

RT. Therefore, low-LET C-ion RT increased the SER. This is one of the hypotheses proposed for the mechanism of the radiosensitizing effect, and further research on the relationship between the radiosensitizing effect and DNA-damaging or DNA-repair-inhibitory effect is warranted.

Our study has certain limitations. Firstly, we performed ${ }^{60} \mathrm{Co}$ gamma-ray and $\mathrm{C}$-ion beam irradiation only on a single cell line and used a single anticancer drug. Secondly, we assessed the effect of irradiation only on the survival of cancer cells, not of normal cells. The assessment of normal tissues is essential in clinical settings to test for side-effects. However, we believe our study is valuable as it is the first to evaluate the cell-killing effect of ${ }^{60} \mathrm{Co}$ gamma-ray and $\mathrm{C}$-ion beam irradiation at various LET levels, and the radiosensitizing effects of $\mathrm{C}$-ion beams at low LET in combination with cisplatin.

In conclusion, this study demonstrated the cell-killing effect of ${ }^{60} \mathrm{Co}$ gamma-ray and $\mathrm{C}$-ion beam irradiation at different LET levels, as well as the radiosensitizing effect of C-ion RT at different LET levels combined with cisplatin. We also showed that low-LET C-ion beams have a superior cell-killing effect to that of ${ }^{60} \mathrm{Co}$ gamma rays, and survival curves similar to those under ${ }^{60} \mathrm{Co}$ gamma-ray RT. Additionally, C-ion beams at low LET levels in combination with cisplatin exerted a higher radiosensitizing effect. The results of our study have clinical applications for improving anticancer therapies using irradiation.

\section{Conflicts of Interest}

The Authors declare that the research was conducted in the absence of any commercial or financial relationships that could be construed as a potential conflict of interest.

\section{Authors' Contributions}

Conceptualization: S.S., M.W.; methodology: S.S., M.W.; formal analysis: S.S., M.W.; investigation: S.S., M.W.; resources: S.S., M.W.; data curation: S.S., M.W.; writing-original draft preparation: S.S., M.W.; writing-review and editing: S.S., M.W., T.O.; visualization: S.S.; supervision: T.O., T.N.; project administration: M.W.; funding acquisition: T.N.

\section{Acknowledgements}

The Authors would like to thank our colleagues at QST Hospital, Gunma University Heavy-Ion Medical Center, and the Department of Radiation Oncology, Gunma University Graduate School of Medicine. This work was supported by the Research Project with Heavy Ions at the National Institute of Radiological Sciences, Technology of Japan for programs for Leading Graduate Schools, Cultivating Global Leaders in Heavy-Ion Therapeutics and Engineering, and JSPS KAKENHI Grant Number 20K16751.

\section{References}

1 Tsujii H, Kamada T, Shirai T, Noda K, Tsuji H and Karasawa K: Carbon-ion Radiotherapy Principles, Practices, and Treatment Planning. First Edition. Japan: Springer, 2014.

2 Okonogi N, Wakatsuki M, Kato S, Karasawa K, Miyasaka Y, Murata H, Nakano T, Kamada T, Shozu M; Working Group of Gynecological Tumors: A phase 1/2 study of carbon ion radiation therapy with concurrent chemotherapy for locally advanced uterine cervical squamous cell carcinoma (Protocol 1302). Int J Radiat Oncol Biol Phys 104(3): 631-639, 2019. PMID: 30825494. DOI: 10.1016/j.ijrobp.2019.02.042

3 Shirai K, Saitoh JI, Musha A, Abe T, Kobayashi D, Takahashi T, Tamaki T, Kawamura H, Takayasu Y, Shino M, Toyoda M, Takahashi K, Hirato J, Yokoo S, Chikamatsu K, Ohno T, Nakano T; Working Group on Head and Neck Tumors: Prospective observational study of carbon-ion radiotherapy for non-squamous cell carcinoma of the head and neck. Cancer Sci 108: 2039-2044, 2017. PMID: 28730646. DOI: 10.1111/ cas. 13325

4 Saitoh JI, Shirai K, Abe T Kubo N, Ebara T, Ohno T, Minato K, Saito R, Yamada M, Nakano T; Working Group of Lung Tumors: A phase I study of hypofractionated carbon-ion radiotherapy for stage III non-small cell lung cancer. Anticancer Res 38(2): 885891, 2018. PMID: 29374716. DOI: 10.21873/anticanres.12298

5 Shiba S, Abe T, Shibuya K, Katoh H, Koyama Y, Shimada H, Kakizaki S, Shirabe K, Kuwano H, Ohno T and Nakano T: Carbon ion radiotherapy for 80 years or older patients with hepatocellular carcinoma. BMC Cancer 17: 721, 2017. PMID: 29115938. DOI: 10.1186/s12885-017-3724-4

6 Shiba S, Shibuya K, Katoh H, Kaminuma T, Miyazaki M, Kakizaki S, Shirabe K, Ohno T and Nakano T: A comparison of carbon ion radiotherapy and transarterial chemoembolization treatment outcomes for single hepatocellular carcinoma: a propensity score matching study. Radiat Oncol 14(1): 137, 2019. PMID: 31375120. DOI: 10.1186/s13014-019-1347-4

7 Shibuya K, Ohno T, Katoh H Okamoto M, Shiba S, Koyama Y, Kakizaki S, Shirabe K and Nakano T: A feasibility study of highdose hypofractionated carbon ion radiation therapy using four fractions for localized hepatocellular carcinoma measuring $3 \mathrm{~cm}$ or larger. Radiother Oncol 132: 230-235, 2019. PMID: 30366726. DOI: 10.1016/j.radonc.2018.10.009

8 Ohno T, Noda SE, Murata K Ohno T, Noda SE, Murata K, Yoshimoto Y, Okonogi N, Ando K, Tamaki T, Kato S, Hirakawa T, Kanuma T, Minegishi T, Nakano T; Working Group for Gynecologic Cancer: Phase I study of carbon ion radiotherapy and image-guided brachytherapy for locally advanced cervical cancer. Cancers 10(9): 338, 2018. PMID: 30231543. DOI: $10.3390 /$ cancers 10090338 
9 Matsumoto K, Imai R, Kamada T, Maruyama K, Tsuji H, Tsujii H, Shioyama Y, Honda H, Isu K; Working Group for Bone and Soft Tissue Sarcomas: Impact of carbon ion radiotherapy for primary spinal sarcoma. Cancer 119: 3496-3503, 2013. PMID: 23939877. DOI: $10.1002 /$ cncr.28177

10 Imai R, Kamada T and Araki N: Clinical efficacy of carbon ion radiotherapy for unresectable chondrosarcomas. Anticancer Res 37(12): 6959-6964, 2017. PMID: 29187480. DOI: 10.21873/ anticanres. 12162

11 Kanai T, Endo M, Minohara S, Miyahara N, Koyama-ito H, Tomura H, Matsufuji N, Futami Y, Fukumura A, Hiraoka T, Furusawa Y, Ando K, Suzuki M, Soga F and Kawachi K: Biophysical characteristics of HIMAC clinical irradiation system for heavy-ion radiation therapy. Int J Radiat Oncol Biol Phys 44(1): 201-210, 1999. DOI: 10.1016/S0360-3016(98)00544-6

12 Nakano T, Suzuki Y, Ohno T, Kato S, Suzuki M, Morita S, Sato S, Oka K and Tsujii H: Carbon beam therapy overcomes the radiation resistance of uterine cervical cancer originating from hypoxia. Clin Cancer Res 12 (7 Pt 1): 2185-2190, 2006. PMID: 16609033. DOI: 10.1158/1078-0432.CCR-05-1907

13 Cui X, Oonishi K, Tsujii H, Yasuda T, Matsumoto Y, Furusawa Y, Akashi M, Kamada T and Okayasu R: Effects of carbon ion beam on putative colon cancer stem cells and its comparison with X-rays. Cancer Res 71(10): 3676-3687, 2011. PMID: 21454414. DOI: $10.1158 / 0008-5472 . C A N-10-2926$

14 Pearcey R, Brundage M, Drouin P, Jeffrey J, Johnston D, Lukka H, MacLean G, Souhami L, Stuart G and Tu D: Phase III trial comparing radical radiotherapy with and without cisplatin chemotherapy in patients with advanced squamous cell cancer of the cervix. J Clin Oncol 20(4): 966-972, 2002. PMID: 11844818. DOI: $10.1200 / J C O .2002 .20 .4 .966$

15 Rose PG, Ali S, Watkins E, Thigpen JT, Deppe G, Clarke-Pearson DL, Insalaco S; Gynecologic Oncology Group: Long-term followup of a randomized trial comparing concurrent single agent cisplatin, cisplatin-based combination chemotherapy, or hydroxyurea during pelvic irradiation for locally advanced cervical cancer: A Gynecologic Oncology Group study. J Clin Oncol 25(19): 28042810, 2007. PMID: 17502627. DOI: 10.1200/JCO.2006.09.4532

16 Forastiere AA, Zhang Q, Weber RS, Maor MH, Goepfert H, Pajak TF, Morrison W, Glisson B, Trotti A, Ridge JA, Thorstad W, Wagner H, Ensley JF and Cooper JS: Long-term results of RTOG 91-11: A comparison of three nonsurgical treatment strategies to preserve the larynx in patients with locally advanced larynx cancer. J Clin Oncol 31(7): 845-852, 2013. PMID: 23182993. DOI: 10.1200/JCO.2012.43.6097

17 Okonogi N, Wakatsuki M, Kato S, Karasawa K, Kiyohara H, Shiba S, Kobayashi D, Nakano T, Kamada T, Shozu M; Working Group of Gynecological Tumors: Clinical outcomes of carbon ion radiotherapy with concurrent chemotherapy for locally advanced uterine cervical adenocarcinoma in a phase 1/2 clinical trial (Protocol 1001). Cancer Med 7(2): 351-359, 2018. PMID: 29341491. DOI: 10.1002/cam4.1305

18 Shinoto M, Yamada S, Terashima K, Yasuda S, Shioyama Y, Honda H, Kamada T, Tsujii H, Saisho H; Working Group for Pancreas Cancer: Carbon-ion radiation therapy with concurrent gemcitabine for patients with locally advanced pancreatic cancer. Int J Radiat Oncol Biol Phys 95(1): 498-504, 2016. PMID: 26883565. DOI: $10.1016 /$ j.ijrobp.2015.12.362

19 Koto M, Demizu Y, Saitoh JI, Suefuji H, Okimoto T, Ohno T, Shioyama Y, Takagi R, Ikawa H, Nemoto K, Nakano T, Kamada
T; Japan Carbon-Ion Radiation Oncology Study Group: Multicenter study of carbon-ion radiation therapy for mucosal melanoma of the head and neck: Subanalysis of the Japan Carbon-Ion Radiation Oncology Study Group (J-CROS) study (1402 HN). Int J Radiat Oncol Biol Phys 97(5): 1054-1060, 2017. PMID: 28332989. DOI: 10.1016/j.jirobp.2016.12.028

20 Kitabayashi H, Shimada H, Yamada S, Yasuda S, Kamata T, Ando $\mathrm{K}$, Tsujii $\mathrm{H}$ and Ochiai T: Synergistic growth suppression induced in esophageal squamous cell carcinoma cells by combined treatment with docetaxel and heavy carbon-ion beam irradiation. Oncology Rep 15(4): 913-918, 2006. PMID: 16525679.

21 Schlaich F, Brons S, Haberer T, Debus J, Combs ES and Weber $\mathrm{KJ}$ : Comparison of the effects of photon versus carbon ion irradiation when combined with chemotherapy in vitro. Rad Oncol 8: 26, 2013. PMID: 24192264. DOI: 10.1186/1748-717X-8-260

22 Ando K, Koike S, Nojima K, Chen YJ, Ohira C, Ando S, Kobayashi N, Ohbuchi T, Shimizu W and Kanai T: Mouse skin reactions following fractionated irradiation with carbon ions. Int J Radiat Biol 74(1): 129-138, 1998. PMID: 9687982. DOI: $10.1080 / 095530098141799$

23 Kanematsu N, Matsufuji N and Inaniwa T: Estimation of linear energy transfer distribution for broad-beam carbon-ion radiotherapy at the National Institute of Radiological Sciences, Japan. Radiol Phys Technol 11(2): 242-247, 2018. PMID: 29470773. DOI: 10.1007/s12194-018-0444-7

24 Masunaga S, Ando K, Uzawa A, Hirayama R, Furusawa Y, Koike S, Sakurai Y, Nagata K, Suzuki M, Kashino G, Kinashi Y, Tanaka H, Maruhashi A and Ono K: Radiobiologic significance of response of intratumor quiescent cells in vivo to accelerated carbon-ion beams compared with gamma-rays and reactor neutron beams. Int J Radiat Oncol Biol Phys 70(1): 221228, 2008. PMID: 18086390. DOI: 10.1016/j.jrobp.2007.09.021

25 Kubo N, Noda SE, Takahashi A, Yoshida Y, Oike T, Murata K, Musha A, Suzuki Y, Ohno T, Takahashi T and Nakano T: Radiosensitizing effect of carboplatin and paclitaxel to carbonion beam irradiation in the non-small-cell lung cancer cell line H460. J Radiat Res 56(2): 229-238, 2015. PMID: 25599995. DOI: $10.1093 / \mathrm{jrr} / \mathrm{rru} 085$

26 Rave-Fränk M, Schmidberger H, Christiansen H, Boll C, Lehmann $\mathrm{J}$ and Weiss E: Comparison of the combined action of oxaliplatin or cisplatin and radiation in cervical and lung cancer cells. Int J Radiat Biol 83(1): 41-47, 2007. PMID: 17357438. DOI: $10.1080 / 09553000601121108$

27 Oike T, Niimi A, Okonogi N, Murata K, Matsumura A, Noda SE, Kobayashi D, Iwanaga M, Tsuchida K, Kanai T, Ohno T, Shibata A and Nakano T: Visualization of complex DNA double-strand breaks in a tumor treated with carbon-ion radiotherapy. Sci Rep 6: 22275, 2016. PMID: 26925533. DOI: 10.1038/srep22275

28 Zamble DB and Lippard SJ: Cisplatin and DNA repair in cancer chemotherapy. Trends Biochem Sci 20: 435-439, 1995. PMID: 8533159. DOI: 10.1016/s0968-0004(00)89095-7

29 Cohen SM and Lippard SJ: Cisplatin: from DNA damage to cancer chemotherapy. Prog Nucleic Acid Res Mol Biol 67: 93130, 2001. DOI: 10.1016/S0079-6603(01)67026-0

Received July 29, 2020

Revised August 9, 2020

Accepted August 10, 2020 